\title{
LATINOAMÉRICA EN PISA 2012: FACTORES ASOCIADOS A LA ALFABETIZACIÓN MATEMÁTICA
}

\author{
Andrés Fernández Aráuz ${ }^{1}$
}

Recibido: 23/06/2016

Aprobado: 05/04/2017

\begin{abstract}
RESUMEN
Ocho países de la región latinoamericana participaron de la evaluación PISA 2012, obteniendo pobres resultados en la evaluación matemática. Al analizar los factores que se asocian con este desempeño, los resultados de esta investigación muestran que la asistencia a la educación preescolar juega un rol importante en el rendimiento futuro de los estudiantes. Además, incluso controlando por variables tradicionalmente relacionadas con el rendimiento como el estatus socioeconómico del hogar, o el nivel educativo de los padres, esta investigación muestra que los factores personales tienen una gran relevancia al momento de explicar las diferencias en los resultados: el autoconcepto de los estudiantes en el área matemática, su interés hacia esta materia y la familiaridad con conceptos matemáticos son variables que resultaron importantes para predecir los puntajes en la prueba PISA.
\end{abstract}

PALABRAS CLAVE: COEFICIENTES ESTANDARIZADOS, CORRELACIÓN INTRACLASE, MODELO MULTINIVEL.

\section{ABSTRACT}

Eight countries in Latin America participated in the PISA 2012 assessment, obtaining poor results in mathematics assessment. In analyzing the factors associated with this performance, the results of this research show that attendance at preschool education plays an important role in the future student performance. Moreover, even controlling for variables traditionally associated with performance as the socioeconomic status of the household or the educational level of parents, this research shows that personal factors have a great importance when explaining the differences in outcomes: self-concept students in the math area, their interest towards mathematics and familiarity with mathematical concepts are variables that were significant to predict scores on the PISA test.

KEYWORDS: STANDARDIZED COEFFICIENTS, INTRA CLASS CORRELATION, MULTILEVEL MODEL.

1 Ministerio de Educación Pública, Departamento de Análisis Estadístico. Código postal 10102. San José Costa Rica; affa17@gmail.com 


\section{INTRODUCCIÓN}

En el año 2012, ocho países latinoamericanos participaron en la evaluación internacional PISA, mediante la aplicación de una prueba estandarizada a una muestra de jóvenes en edad de 15 años. En noviembre del 2013 fueron publicados los resultados, que ubican a la región latinoamericana muy por debajo de los resultados que obtienen los estudiantes de los países miembros de la Organización para la Cooperación y el Desarrollo Económico.

Si bien el resultado no es novedoso, ya que continúa la tendencia que se mostraba en las evaluaciones previas a esta, es la primera ocasión en que tantos países latinoamericanos participan simultáneamente en la prueba PISA, cuyo énfasis es matemáticas, ya que en la ocasión anterior (2003) únicamente cuatro países de la zona tomaron la prueba con énfasis matemático, por lo que la evaluación del 2012 permite realizar un análisis más extenso de los factores asociados a la alfabetización matemática de la juventud latinoamericana.

Más allá de los resultados generales, los datos obtenidos a través de la evaluación de PISA, junto con la información disponible gracias a los cuestionarios aplicados a estudiantes y directores de los centros educativos del nivel secundario, permiten elaborar una idea de la calidad de los sistemas educativos latinoamericanos y nos brinda la oportunidad de conocer las diferencias educativas que existen a lo interno de la región.

Este artículo tiene como objetivos realizar un análisis detallado del rendimiento de los jóvenes latinoamericanos en la evaluación de PISA del año 2012 y de algunos factores que se asocian con el desempeño de los estudiantes en la prueba.

\section{¿En qué consiste la evaluación PISA?}

El Programa Internacional de Evaluación de Estudiantes (PISA- Programme for International Student Assessment) es un esfuerzo conjunto entre los países miembros de la OCDE que busca medir la capacidad que tienen los estudiantes en edad de 15 años, que se acercan a concluir el ciclo de escolaridad obligatoria, para afrontar los retos de la sociedad actual.

La evaluación tiene una visión a futuro: en lugar de centrarse en evaluar conocimientos específicos de acuerdo con los currículos o planes de estudio de cada país, se evalúa la capacidad que tienen los estudiantes para utilizar su conocimiento $y$ habilidades para afrontar retos de la vida real.

Las encuestas $y$ evaluaciones de PISA se realizan cada tres años $y$, aunque todas miden habilidades y conocimientos en lectura, ciencias y matemáticas, cada evaluación enfatiza en una de estas tres áreas, dedicando cerca del 60\% de los ítems a la evaluación del área en la que se enfoca la prueba.

La primera de estas evaluaciones se aplicó en el año 2000 y tuvo énfasis en el área de lectura; en esta evaluación participaron 43 países. La segunda prueba se aplicó en el año 2003, se concentró en las matemáticas y contó con la participación de 41 países. La tercera ocasión en que se evaluó estudiantes con la metodología de PISA fue en el año 2006, y concentró mayores esfuerzos en evaluar los conocimientos y habilidades en ciencias; ese año participaron 58 países. Con estas tres pruebas, concluyó el primer ciclo completo de evaluaciones de PISA.

El segundo ciclo de pruebas se inició en el año 2009 con la evaluación que enfatiza lectura y participaron 74 países $^{2}$. La penúltima evaluación de PISA se llevó a cabo en el 2012 con la participación de 65 países, y es de esta evaluación que se obtiene los datos analizados en este artículo.

2 En esta evaluación, 65 países participaron en el 2009 y otros 9 tomaron la prueba en el año 2010, bajo el proyecto denominado PISA 2009 PLUS. 
En este año, el área modular de evaluación fue matemáticas. La última de estas evaluaciones se realizó recientemente en el año 2015, cuyos resultados serán conocidos hasta finales del año 2016.

En el caso particular de Latinoamérica, nueve son los países que han formado parte en algún momento de la evaluación PISA, aunque solo tres han participado en las seis evaluaciones realizadas hasta el momento (Brasil, Chile y México). Argentina y Uruguay únicamente se ausentaron en una medición, mientras que Colombia y Perú no participaron en dos de ellas. Por último, Costa Rica ingresó al proyecto en el año 2009 y ha participado en las tres evaluaciones realizadas desde ese momento, mientras que Panamá solamente participó en la evaluación del año 2009, y por el pobre rendimiento promedio de sus estudiantes, el Ministerio de Educación Panameño decidió no participar más en esta evaluación, mientras realizan las reformas educativas pertinentes.

CUADRO 1

PARTTICIPACIÓN DE PAÍSES LATINOAMERICANOS EN LA EVALUACIÓN PISA

\begin{tabular}{lcccccc}
\hline País & 2000 & 2003 & 2006 & 2009 & 2012 & 2015 \\
\hline Argentina & SÍ & NO & SÍ & SÍ & SÍ & SÍ \\
Brasil & SÍ & SÍ & SÍ & SÍ & SÍ & SÍ \\
Chile & SÍ & SÍ & SÍ & SÍ & SÍ & SÍ \\
Colombia & NO & NO & SÍ & SÍ & SÍ & SÍ \\
Costa Rica & NO & NO & NO & SÍ & SÍ & SÍ \\
México & SÍ & SÍ & SÍ & SÍ & SÍ & SÍ \\
Perú & SÍ & No & NO & SÍ & SÍ & SÍ \\
Uruguay & NO & SÍ & SÍ & SÍ & SÍ & SÍ \\
Panamá & NO & NO & No & SÍ & NO & NO \\
\hline
\end{tabular}

Fuente: Elaboración propia con datos de la evaluación PISA.

Así las cosas, para este artículo serán analizadas la participación de ocho países latinoamericanos en la prueba del año 2012.

Además de la medición de habilidades y conocimientos de los estudiantes mediante una prueba escrita, PISA también realiza cuestionarios para recolectar información que permita analizar y contextualizar adecuadamente los resultados de las pruebas. Se aplican cuestionarios a los estudiantes para obtener información sobre aspectos del hogar y la familia; así como a los directores de cada centro educativo, para indagar información específica sobre los aspectos propios de la infraestructura del centro educativo, cantidad y preparación del personal docente, entre otros.

\section{Los resultados de PISA 2012}

Los valores del rendimiento de los estudiantes en las evaluaciones de PISA son considerados como variables latentes continuas, lo que significa que se tratan como cantidades que son medibles, pero para las que no existe un instrumento de medida, ya que los ítems no son evaluados con puntuaciones específicas, sino que PISA define escalas a partir de las cuales se realizan las comparaciones. Así, para facilitar la interpretación de las notas asignadas a los estudiantes, las escalas en lectura, matemáticas y ciencias fueron diseñadas para tener una nota promedio de 500 puntos y una desviación estándar de 100 puntos para los países miembros de la OECD. Esto significa que cerca de dos tercios del estudiantado de países 
miembros de la OECD obtienen notas entre los 400 y 600 puntos (OECD, 2009). A estos valores del rendimiento de los estudiantes se les llama valores plausibles.

En todas las áreas, Shanghái (China) fue la economía que obtuvo el mejor promedio: 570 en lectura, 613 en matemáticas y 580 en ciencias.

En matemáticas, los países latinoamericanos aparecen en el último tercio de la lista, y todos tuvieron rendimientos promedio inferiores a la media de los países miembros de la OECD (ver cuadro 2). Chile se ubica en el primer lugar en matemáticas en Latinoamérica, con 423 puntos. El segundo lugar en la región lo ocupan México, Uruguay y Costa Rica, debido a que aunque la estimación puntual del promedio es distinta en cada nación, no existe diferencia estadísticamente significativa al 95\% de confianza. Brasil, Argentina, Colombia y Perú son los cuatro países latinoamericanos con peor rendimiento en matemáticas, con puntajes inferiores a los 400 puntos. Perú es, de hecho, el país que ocupa el último lugar en el ranking elaborado por PISA a nivel mundial en las tres evaluaciones ${ }^{3}$.

CUADRO 2

PUNTUACIÓN PROMEDIO DE LOS PAÍSES LATINOAMERICANOS SEGÚN ÁREA EVALUADA EN LA PRUEBA DE PISA. 2012

\begin{tabular}{|c|c|c|c|c|c|c|c|c|c|c|c|c|c|c|}
\hline \multicolumn{5}{|c|}{ Matemáticas } & \multicolumn{5}{|c|}{ Lectura } & \multicolumn{5}{|c|}{ Ciencias } \\
\hline $\begin{array}{l}\text { Latino } \\
\text { América }\end{array}$ & $\begin{array}{l}\text { Gene- } \\
\text { ral }\end{array}$ & País & Promedio & E.E & $\begin{array}{c}\text { Latino } \\
\text { América }\end{array}$ & $\begin{array}{l}\text { Gene- } \\
\text { ral }\end{array}$ & País & $\begin{array}{l}\text { Prome- } \\
\text { dio }\end{array}$ & E.E & $\begin{array}{c}\text { Latino } \\
\text { América }\end{array}$ & $\begin{array}{l}\text { Gene- } \\
\text { ral }\end{array}$ & País & Promedio & E.E \\
\hline 1 & 50 & Chile & 423 & 3,1 & 1 & 45 & Chile & 441 & 2,9 & 1 & 45 & Chile & 445 & 2,9 \\
\hline \multirow[t]{3}{*}{2} & 52 & Mexico & 413 & 1,4 & & 47 & $\begin{array}{l}\text { Costa } \\
\text { Rica }\end{array}$ & 441 & 3,5 & 2 & 50 & $\begin{array}{l}\text { Costa } \\
\text { Rica }\end{array}$ & 429 & 2,9 \\
\hline & 54 & $\begin{array}{l}\text { Uru- } \\
\text { guay }\end{array}$ & 409 & 2,8 & 2 & 51 & Mexico & 424 & 1,5 & 3 & 53 & $\begin{array}{l}\text { Uru- } \\
\text { guay }\end{array}$ & 416 & 2,8 \\
\hline & 55 & $\begin{array}{l}\text { Costa } \\
\text { Rica }\end{array}$ & 407 & 3,0 & 3 & 53 & $\begin{array}{l}\text { Uru- } \\
\text { guay }\end{array}$ & 411 & 3,2 & & 54 & $\begin{array}{l}\text { Mexi- } \\
\text { co }\end{array}$ & 415 & 1,3 \\
\hline \multirow[t]{2}{*}{3} & 57 & Brazil & 391 & 2,1 & & 54 & Brazil & 410 & 2,1 & 4 & 57 & $\begin{array}{l}\text { Ar- } \\
\text { gen- } \\
\text { tina }\end{array}$ & 406 & 3,9 \\
\hline & 58 & $\begin{array}{l}\text { Argen- } \\
\text { tina }\end{array}$ & 388 & 3,5 & & 56 & $\begin{array}{l}\text { Colom- } \\
\text { bia }\end{array}$ & 403 & 3,4 & & 58 & $\begin{array}{c}\text { Bra- } \\
\text { zil }\end{array}$ & 405 & 2,1 \\
\hline \multirow[t]{2}{*}{4} & 61 & $\begin{array}{l}\text { Co- } \\
\text { lombia }\end{array}$ & 376 & 2,9 & 4 & 60 & $\begin{array}{c}\text { Argen- } \\
\text { tina }\end{array}$ & 396 & 3,7 & & 59 & $\begin{array}{l}\text { Co- } \\
\text { lom- } \\
\text { bia }\end{array}$ & 399 & 3,1 \\
\hline & 64 & Perú & 368 & 3,7 & & 64 & Peru & 384 & 4,3 & 5 & 64 & Peru & 373 & 3,6 \\
\hline
\end{tabular}

Fuente: Elaboración propia con datos de la evaluación internacional PISA 2012.

E.E: Error estándar.

En la evaluación de lectura, Chile y Costa Rica comparten el primer lugar en Latinoamérica, con 441 puntos cada uno, aunque siempre ubicados en la tercera parte más baja del ranking mundial. En ciencias, la situación es similar.

3 Es importante considerar que la representatividad de la muestra de cada país sobre la población de 15 años es distinta y, en el caso de Costa Rica, llega incluso a ser de apenas el $50 \%$, por lo que esto introduce un sesgo de selección, ya que al no tomar en cuenta la otra mitad de la población de 15 años que no asiste al sistema educativo -que se espera que muestra niveles de rendimiento más bajos al ser excluidos del proceso formal de educación- únicamente se pueden inferir los resultados hacia la población estudiantil. 


\section{Escalas de competencia}

PISA no solo reporta el rendimiento de los estudiantes como un puntaje general, sino también en términos del contenido evaluado, ubicando a los alumnos en una escala que describe su conocimiento y habilidades.

A estas escalas se les llama "escalas de competencia" en lugar de "escalas de desempeño", ya que reportan lo que los estudiantes saben y pueden hacer a ciertos niveles, en lugar de lo que hicieron los estudiantes en la evaluación (una única ocasión). Se establece así, ya que PISA está interesado en obtener el nivel de competencia general del estudiante, y no el rendimiento mostrado en una prueba específica.

El diseño de la evaluación de la prueba de PISA permite lo anterior, al utilizar técnicas modernas de modelación de respuestas a los ítems para estimar, simultáneamente, la habilidad de toda la población estudiantil que fue evaluada y la dificultad de todos los ítems de la evaluación. La metodología de PISA se basa en muestras de estudiantes y de ítems para efectuar estimaciones poblacionales: una muestra de estudiantes de 15 años de edad es seleccionada para representar a toda la población de 15 años del país, y una muestra de ítems de un gran conjunto de estos es administrada a cada estudiante.

La relación entre la habilidad del estudiante y la dificultad de los ítems es probabilística, lo que quiere decir que existe cierta probabilidad de que un estudiante particular pueda completar correctamente algún ítem. Con esta información, los expertos en PISA definieron seis niveles de competencia en matemática, que van desde el nivel 1, que indica que el alumno posee la capacidad de resolver problemas y ejercicios matemáticos rutinarios, hasta el nivel 6, donde este es capaz de resolver problemas que requieren de razonamiento y habilidades matemáticas avanzadas.

CUADRO 3

PORCENTAJE DE ESTUDIANTES POR NIVEL DE COMPETENCIA EN MATEMÁTICAS SEGÚN PAÍS EN PISA 2012

\begin{tabular}{lccc}
\hline País & Debajo Nivel 2 & Nivel 2 & Encima Nivel 2 \\
\hline Chile & 51,5 & 25,3 & 23,1 \\
Uruguay & 55,8 & 23,0 & 21,2 \\
Mexico & 54,7 & 27,8 & 17,5 \\
Costa Rica & 59,9 & 26,8 & 13,3 \\
Brasil & 67,1 & 20,4 & 12,5 \\
Argentina & 66,5 & 22,2 & 11,3 \\
Peru & 74,6 & 16,1 & 9,3 \\
Colombia & 73,8 & 17,8 & 8,4 \\
\hline
\end{tabular}

Fuente: Elaboración propia con datos de la evaluación PISA 2012.

PISA considera al nivel 2 como el nivel básico de competencias, en el que los estudiantes comienzan a demostrar las habilidades en matemáticas que les permitirá participar eficazmente en la vida productiva.

De esta manera, alrededor del 60\% de los estudiantes de 15 años de Latinoamérica ni siquiera alcanzan el nivel básico de comprensión matemática. En todos los países, más de la mitad de sus estudiantes obtuvieron puntuaciones en la escala matemática por debajo del nivel básico, siendo incluso de hasta un $74 \%$ de los estudiantes en los casos de Perú y Colombia, mientras que solo en Chile, Uruguay, México y Costa Rica una cuarta parte muestra el nivel básico de alfabetización matemática (ver cuadro 3). 
Cabe resaltar, además, que debido al pobre rendimiento matemático de varios países no miembros de la OCDE, incluidos los de Latinoamérica, tuvo que ser creado un nivel adicional. La escala de competencia ordinaria varía del nivel 1 al nivel 6, pero algunos estudiantes tuvieron tan pobre desempeño que se adicionó el nivel llamado "por debajo del nivel 1", que agrupa, en promedio, al 30\% de los estudiantes de países latinos.

\section{Factores asociados al rendimiento educativo}

La literatura sobre factores asociados con el rendimiento educativo o cognitivo es vasta. El Informe Coleman (Coleman, 1966) fue uno de los primeros estudios desarrollados sobre este tema $y$ aún tiene una influencia significativa en las investigaciones acerca del rendimiento educativo. En él se sugiere que las diferencias en los factores escolares tienen poco que ver con las diferencias en rendimiento, mientras que los factores familiares son más importantes.

En esta misma línea, Hanushek (1986) realiza una revisión de todos los estudios desarrollados hasta mediados de la década de 1980, encontrando que la evidencia del efecto del nivel de gasto por estudiante $u$ otros factores escolares en el rendimiento educativo es extremadamente débil y desaparece cuando se toman en cuenta las diferencias en los factores familiares.

Desde entonces, se han realizado una gran cantidad de investigaciones sobre este tema, utilizando distintas bases de datos en decenas de países, con diferentes metodologías estadísticas, para varios niveles educativos y en general, estudiando diversas aristas de los factores que podrían tener efectos en la mejora del rendimiento educativo.

Al ser tantos los estudios, no es posible analizarlos todos y cada uno en esta sección. Sin embargo, resulta de vital importancia garantizar el análisis de al menos algunos de los más representativos, especialmente, por la rigurosidad de la metodología estadística aplicada.

En un artículo titulado School Resources and Educational Outcomes in Developing Countries: A Review of the Literature from 1990 to 2010, Glewwe et al. (2011) realizan una revisión de las investigaciones sobre factores asociados al rendimiento educativo, pero limitando el periodo de análisis desde 1990 y hasta el año 2010, justificando el utilizar únicamente este periodo y no años anteriores en que, a su criterio, los estudios más antiguos en esta materia se encontraban muy limitados en el tipo y calidad de las metodologías estadísticas que podían ser aplicadas y que, por lo tanto, en los estudios más recientes pudieron aplicarse análisis estadísticos más sofisticados.

Para esto, los autores realizaron un estudio de meta-análisis de trabajos que analizaran los factores asociados al rendimiento educativo. Su revisión de literatura se enfocó en investigaciones sobre educación primaria y secundaria, es decir, no incluye educación preescolar, vocacional o universitaria, y que utilizaran el aprendizaje escolar como variable respuesta (usualmente medido en términos de puntajes en pruebas). Además, debido al consenso de que las variables personales y familiares son en general las que muestran más relación con resultados académicos, y a la ambigüedad de los efectos de variables de los centros educativos y de los profesores, limitan su enfoque al análisis de investigaciones que utilizan variables escolares y del cuerpo docente, sin entrar en consideración de los factores personales y familiares.

Para el meta-análisis, la estrategia utilizada fue buscar una gran variedad de fuentes (más de 9.000 artículos) y eliminar sistemáticamente los trabajos que no cumplían con una serie de criterios definidos por los autores acerca de relevancia y calidad, lo que los lleva a analizar 79 artículos, de los cuales 43 son clasificados como de "alta calidad" por las metodologías estadísticas aplicadas.

Aprovechando esta revisión sistemática de literatura, esta sección se basa en los resultados de los 43 artículos más relevantes de acuerdo con los criterios de los autores.

De los 43 estudios seleccionados, 13 corresponden a diseños experimentales. A diferencia de los estudios que utilizan datos observacionales, los diseños experimentales sí permiten probar 
hipótesis de causalidad planteadas previamente por los investigadores, asignando aleatoriamente a los individuos en los grupos de control $y$ de tratamiento, $y$ evaluando el efecto de un tratamiento al comparar ambos grupos.

En el área de educación, el uso de diseños experimentales no es tan común debido a problemas metodológicos propios que surgen de la compleja interacción entre individuos que no permite controlar todos los factores dentro del experimento, así como por cuestiones éticas y políticas.

Sin embargo, ha habido esfuerzos por desarrollarlos para analizar factores asociados al rendimiento educativo, aunque la mayoría se enfocan en el análisis de programas específicos que podrían tener un impacto sobre el desempeño escolar y que pueden ser manipulados fácilmente en un experimento, por lo que no fue posible encontrar en la literatura a la que se tuvo acceso, ensayos aleatorios controlados que estudiaran las características de los profesores o de los directores, debido a que estos son muy difíciles de aleatorizar.

Las características de infraestructura y de materiales pedagógicos que fueron analizados son los libros de texto, las computadoras y las pizarras. Dos de los experimentos examinan los libros de texto, uno en Filipinas (Tan, Lane, \& Lassibille, 1999) y otro en Kenya (Glewwe, Kremer, \& Moulin, 2007). Los resultados en ambos sugieren que no hay un impacto positivo de proveer libros de texto.

La variable que ha sido más estudiada (en 5 de los 13 experimentos) es la disponibilidad de computadoras y aparatos electrónicos para uso pedagógico. En este caso, algunos autores encuentran resultados positivos, mientras otros, resultados negativos.

Por ejemplo, en su artículo Banerjee, Cole, Duflo, y Linden (2007) evalúan una intervención en escuelas primarias de la India en la que los profesores recibieron capacitación en el uso de software para la enseñanza de la matemática dentro de la clase. En las escuelas pertenecientes al grupo de tratamiento, los estudiantes usan el software de dos a cuatro horas a la semana. Después de dos años de tratamiento, se encontró evidencia de que los estudiantes del grupo de tratamiento tuvieron puntuaciones significativamente más altas en pruebas matemáticas que el grupo de control, pero no se hallaron diferencias significativas en los puntajes en las pruebas de lectura.

Otro estudio (Barrera-Osorio \& Linden, 2009) evaluaron el programa de Computadoras para la Educación en Colombia y encontraron resultados menos concluyentes. En este programa, los profesores recibieron computadoras y ocho meses de capacitación en su uso en la clase, y al final del experimento no se encontraron diferencias en los resultados de las pruebas matemáticas y de lectura evaluadas entre el grupo de control y tratamiento al combinar los resultados de los grados escolares analizados (de tercero a noveno), e incluso resultados positivos en noveno grado, pero resultados significativamente negativos en octavo grado.

En otro estudio, Cristia et al. (2010) evalúan la hipótesis de si el incremento en el acceso a las tecnologías de información y comunicación puede aumentar los años de educación completos en Perú, ya que en el 2004 se implementó un programa educativo financiado por el Banco Interamericano de Desarrollo en el que se distribuyeron 10 computadoras en 350 centros educativos públicos de secundaria; concluyen que no hay evidencia de que la política tuviera un impacto significativo sobre los rendimientos educativos.

En un estudio similar realizado también en Perú, Cristia (2012) evalúan en un experimento aleatorio otro programa que ha tenido gran auge a nivel mundial llamado Una Computadora por Estudiante (One Laptop Per Child Program, OLPC). Este programa busca mejorar el aprendizaje en las regiones más pobres del mundo, proveyendo computadoras personales a los niños para utilizar tanto en la escuela como en el hogar. Perú es el país en el que este programa se ha implementado a mayor escala, incluyendo la distribución de 902.000 computadoras en 319 escuelas públicas en comunidades pobres y rurales. Llegan a la siguiente conclusión: "Los resultados sugieren efectos limitados sobre el rendimiento escolar de los niños, pero impactos positivos en las habilidades cognitivas y competencias relacionadas con el uso de las computadoras" (p. 16). 
Además del uso de computadoras, otros experimentos han analizado la forma en que los centros educativos se encuentran organizados. Por ejemplo, Muralidharan y Sundararaman (2013) estudian el impacto del tamaño de clase en el rendimiento educativo en la India.

En el experimento aleatorio controlado, el tamaño de clase fue intencionalmente reducido en el grupo de tratamiento mediante la contratación de más docentes para distribuir a los estudiantes. El artículo muestra cinco estimaciones del impacto del tamaño de la clase en rendimiento de los estudiantes, de las cuales tres son negativas (como es esperado, a mayor tamaño de clase menor rendimiento) y estadísticamente significativas mientras que las otras dos estimaciones no resultaron significativas.

Sin embargo, Glewwe y otros (2011) sugieren que este experimento no puede tomarse como válido, debido a que los autores no lograron separar el efecto el tamaño de clase del efecto de la contratación de los nuevos docentes; además, al ser el único experimento que hallaron que analiza este tema, consideran que es difícil poder generalizar estos resultados.

Otro de los experimentos indagó sobre el impacto de proveer alimentos en los centros educativos (Tan, Lane, \& Lassibille, 1999), encontrando un resultado no significativo de este tipo de programas en Filipinas. Las clases remediales impartidas por tutores particulares también han sido estudiadas en el Programa de tutorías Balsakhi en la India (Banerjee, et al., 2007), en el que los autores encontraron que el proveer de estos tutores a niños rezagados en el currículo académico aumenta significativamente sus puntajes en las pruebas.

En contraste con los diseños experimentales, hay centenas de estudios que utilizan datos observaciones para realizar sus análisis. Al analizar los que aplican metodologías estadísticas más avanzadas que la típica regresión lineal, Glewwe y otros (2011) hallan que en 30 estudios, la premisa de que los libros de texto y materiales similares mejoren el aprendizaje de los estudiantes es bastante débil, por lo que no es posible tener claridad sobre su efecto.

Por el contrario, en la mayoría de estas investigaciones que utilizaron variables como la calidad y cantidad de escritorios, mesas y sillas dentro del aula, identificaron una relación positiva entre estos y el rendimiento educativo, mientras que los que utilizan variables como computadoras, conexión a Internet y otras relacionadas, encuentran resultados débiles de asociación con la variable respuesta. Estos hallazgos en conjunto con los presentados en la subsección de experimentos muestran que en el tema de las tecnologías de información y comunicación los resultados aún no son concluyentes, $y$ deben tomarse con precaución al momento de establecer políticas educativas.

Al estudiar las variables relacionadas con los docentes, dos de las variables más utilizadas son el nivel educativo de los profesores y su experiencia. En su revisión, Glewwe y otros (2011) obtuvieron resultados ambiguos, ya que en trece de las investigaciones, diez estiman resultados no significativos (e incluso divididos entre efectos positivos y efectos negativos), mientras que dos encuentran resultados positivos significativos, un estudio muestra un resultado estadísticamente significativo pero negativo, al contrario de lo que la teoría muestra que debería ser la relación entre estas variables y el aprendizaje de los estudiantes.

Otras variables como la competencia de los profesores y su conocimiento de la materia que imparten sí muestran efectos positivos muy fuertes. De las 20 estimaciones de este tipo en los estudios seleccionados por el meta-análisis (Glewwe y otros, 2011), todas estiman efectos positivos y en 13 de estas se reportan efectos estadísticamente significativos. Estos resultados muestran bastante evidencia en favor de la hipótesis de que el conocimiento real de los profesores (y no su aproximación mediante su titulación académica) juega un rol sumamente importante en el aprendizaje de los estudiantes.

En el caso de las variables relacionadas con el centro educativo, una de las más utilizadas es la proporción de estudiantes por profesor. En la mayoría de los estudios que incorporan esta variable en sus modelos, el efecto estimado es negativo, como lo explica la teoría, pero no en todos la estimación es significativa, lo que nuevamente sugiere que si bien disminuir el tamaño de una clase tiene 
un impacto positivo en el aprendizaje de los estudiantes, su efecto podría no ser tan contundente como se esperaría.

Al estudiar el abstencionismo de los profesores, los seis estudios que lo hicieron, encontraron todos efectos negativos y en cuatro de estos el efecto es significativo. Otras variables son el número de horas de clases diarias y las tutorías, con resultados ambiguos, ya que algunos estudios encuentran efectos positivos, otros negativos, $y$ la mayor parte de estos con poca significancia estadística.

En Costa Rica, Moreira (2009) analiza la influencia de diversos factores en las puntuaciones obtenidas por estudiantes de undécimo año de colegios académicos diurnos en la prueba nacional de bachillerato de matemáticas del año 2004; a través del análisis multinivel, el autor deduce que los factores endógenos como el historial académico del estudiante, y específicamente, la condición de repitencia y el nivel educativo de los padres, se relacionan con diferencias en las puntuaciones obtenidas. Los resultados se refieren a una muestra probabilística, estratificada y proporcional de estudiantes provenientes de colegios públicos académicos diurnos de Costa Rica. Se utilizó un modelo de regresión múltiple.

Rojas (2004) estudia, mediante un modelo jerárquico, los factores asociados a la repitencia de los alumnos en sétimo año de colegios académicos, diurnos y públicos de Costa Rica, con una muestra de 1442 estudiantes y 115 docentes que impartían clases de las asignaturas de Inglés, Español, Estudios Sociales, Ciencias y Matemáticas. Encuentra que variables como una mala relación de los padres con el estudiante así como una mala interacción entre profesor y estudiante tienen una relación directa con la repitencia.

Además, muestra que factores como una mayor autoestima y motivación, realizar más tareas, recibir ayuda para realizarlas, respeto percibido por los estudiantes de sus iguales, residir con ambos padres durante el tiempo lectivo, indicadores de condición socioeconómica del estudiante y su familia, e indicadores de la infraestructura e instalaciones del centro educativo, incluyendo el acceso a Internet son factores que tienen una relación inversa con la condición de repitencia.

Fernández y Del Valle (2013) intentan responder a la pregunta de si la desigualdad en los resultados de los puntajes en la prueba PISA se debe en gran medida a las diferencias entre los estudiantes que asisten a colegios públicos o a colegios privados.

Para intentar responder a esta pregunta, los autores plantean un modelo de regresión lineal sin corrección multinivel, con el objetivo de poder aplicar una técnica de descomposición de la varianza que permita identificar si la proporción de varianza explicada por la variable del sector del colegio (controlando por otros factores que describe la teoría como importantes) es significativa en la explicación de las diferencias en los resultados educativos.

Sus resultados muestran que, en general, los factores escolares (incluyendo el sector del colegio) no tienen un gran peso en la variabilidad de los resultados, y más bien son los factores familiares, pero particularmente la condición de repitencia de los estudiantes costarricenses, los que más explican la variabilidad en la varianza de las puntuaciones.

En un estudio similar, Giménez y otros (2014) plantean la pregunta: ¿por qué los estudiantes de colegios públicos y privados de Costa Rica obtienen distintos resultados académicos? Para dar respuesta, llevan a cabo un análisis econométrico que, mediante la utilización de funciones de producción educativa y estimaciones por mínimos cuadrados ordinarios con errores estándar corregidos utilizando clústeres por centros educativos, permite cuantificar las diferencias en resultados en pruebas de Matemáticas, Comprensión Lectora y Ciencias entre centros públicos y privados. Aunque las diferencias halladas son importantes, se reducen en más de la mitad cuando se controla por las características de los alumnos (sexo, haber cursado preescolar, confianza en sus capacidades, ser repetidor) y sus hogares (nivel de estudio de los padres, riqueza y posesiones culturales).

Además, mediante el método de descomposición de Oaxaca-Blinder, en ese estudio se profundiza en cuáles son las posibles razones de estas diferencias en resultados. Concluyen que la mayor parte de las diferencias en resultados entre centros públicos y privados es explicada por la diferencia 
en dotaciones. En concreto, el principal factor de la divergencia en rendimiento son las características del hogar, seguida de las diferencias en recursos de los centros educativos, las características del estudiante y el ambiente de trabajo de los centros.

Montero et al. (2013) utilizan modelos de regresión con corrección multinivel con la base de datos de PISA 2009, y demuestran que las variables relacionadas con dimensiones de lectura tienen, conjuntamente, un peso altísimo en la predicción de las notas, tanto en Competencia Lectora como en Alfabetización Matemática.

De acuerdo con los resultados de este estudio, aproximadamente un 43\% de la varianza de los puntajes se explica por factores asociados al estudiante y un $12 \%$ por factores asociados a la institución.

De hecho, el estudio va más allá y elabora un perfil de un típico estudiante de alto rendimiento, que incluye lo siguiente: cursa un grado mayor al que debería estar de acuerdo con su edad, mejor actitud hacia la lectura, usa mejores estrategias para comprender y resumir textos escolares, no es repitente, valora su colegio, lee por gusto o por iniciativa propia, su hogar tiene un alto índice de posesión de bienes, entre otros. El único factor relacionado con la institución que aparece en este perfil es asistir a un centro educativo ubicado en un distrito con altos valores del índice de desarrollo social.

Como continuación a este estudio, recientemente Montero, Rojas y Zamora (2014) vuelven a analizar los resultados de la prueba PISA con un modelo de regresión con corrección multinivel y, de la misma manera, fueron identificadas variables que son importantes en la predicción de los puntajes de las tres pruebas de PISA y que, a su vez, pueden ser objeto de intervenciones pedagógicas o de políticas educativas, con el objetivo de lograr mejores rendimientos en dichas pruebas. Encuentran que el número de libros en el hogar es una de las variables predictoras importantes para la Alfabetización Matemática, puesto que se puede considerar un indicador "proxy" de dimensiones de lectura, las cuales fueron, conjuntamente, el factor predictivo más importante para el puntaje en las pruebas PISA del año 2009.

Además, otros factores con gran importancia predictiva son el número de horas semanales que se dedica a la realización de tareas, un alto valor en la escala de familiaridad con conceptos matemáticos, un alto valor en la escala de autoeficacia en matemáticas, un alto valor en la escala de actitud hacia lo aprendido en el colegio, el haber asistido a educación preescolar y un alto valor en la cantidad de docentes de matemáticas con bachillerato o licenciatura en pedagogía.

Fernández (2013) analiza a los estudiantes costarricenses identificados como "resilientes" en la evaluación PISA 2009; y los compara con sus pares que, a pesar de tener un nivel socioeconómico similar, obtuvieron malos resultados en esta prueba La resiliencia educativa refiere a los estudiantes que, a pesar de vivir bajo condiciones socioeconómicas que les son adversas, lograron obtener excelentes resultados en la evaluación internacional PISA 2009 y así romper el círculo vicioso que hay entre un pobre entorno socioeconómico y un bajo rendimiento educativo.

Mediante el uso de una regresión logística, el modelo fue estimado utilizando tres variables de control: el género, el grado que cursa el estudiante y el promedio del índice estatus económico social y cultural a nivel de centro educativo (efecto de pares).

En este estudio, se identifican cuatro factores principales que podrían estar relacionados con el mejor desempeño en lectura de los estudiantes resilientes: 1) la habilidad para resumir textos, 2) la habilidad para entender y recordar, 3) el gusto por la lectura y 4) la actitud hacia el colegio.

Los dos primeros factores se relacionan con el tipo de estrategias que utilizan los estudiantes para comprender un texto y para transmitir la información aprendida mientras que los dos últimos factores se relacionan más el con valor que los estudiantes le confieren a la lectura y a los deberes académicos.

Finalmente, Fernández (2015) evalúa la hipótesis causal de que el estatus socioeconómico de los estudiantes y la actitud de los estudiantes hacia la matemática son factores que determinan en gran medida los resultados académicos de los estudiantes costarricenses, medido a través del resultado en la prueba de alfabetización matemática de PISA 2012. Para esto, define un modelo de medición de los constructos latentes y estima un modelo de ecuaciones estructurales. 
El estatus socioeconómico de los estudiantes es medido mediante tres variables indicadoras: el índice posesiones del hogar, el índice de estatus ocupacional más alto de los padres, y el índice del nivel educativo más alto de los padres.

La actitud de los estudiantes hacia las matemáticas es una variable latente que intenta capturar la actitud propia de los estudiantes hacia el aprendizaje y la utilización de las matemáticas. Este factor es medido mediante la utilización de tres variables indicadoras: la confianza en la realización de problemas matemáticos, la ansiedad a la hora de enfrentarse a problemas que involucren la utilización de matemáticas y el auto concepto, que mide qué tan bueno o malo se considera el estudiante a sí mismo para las matemáticas.

El autor concluye que el modelo estructural brinda bastante evidencia a favor de la hipótesis de causalidad de que el estatus socioeconómico y la actitud personal del estudiante hacia las matemáticas son determinantes del rendimiento educativo de los estudiantes costarricenses en esta materia, medido a través de los resultados de la prueba de alfabetización matemática de PISA 2012, siendo este un buen punto de partida para formular un modelo más extenso que contemple de mejor manera la complejidad de los factores sociales, institucionales y de contexto que inciden en el rendimiento académico de los jóvenes.

De la revisión de literatura anterior, es evidente que no hay un claro consenso sobre el rol de los factores escolares $y$ del personal docente sobre el rendimiento educativo de los estudiantes $y$, en general, tampoco hay evidencia para afirmar que lo que funciona para un país pueda funcionar para otro.

\section{Alfabetización matemática, según PISA}

Debido a la falta de consenso sobre los factores asociados al rendimiento educativo, este artículo analiza la relación de una serie de variables que podrían incidir en las diferencias en resultados académicos de los países latinos que participaron en PISA 2012, sin ajustarse al análisis de un patrón de causalidad específica, en especial, por lo complicado que resulta plantear este tipo de patrones entre variables, para una región tan disímil como la latinoamericana. En su lugar, este artículo pretende generar mayor evidencia de la posible relación entre factores que tradicionalmente se han asociado con mejoras en el rendimiento educativo, para la región latinoamericana.

Dado que la prueba PISA 2012 tuvo un mayor énfasis en la evaluación matemática, resulta importante comprender el concepto de alfabetización matemática planteado en el marco de referencia de dicha evaluación.

Según PISA (OECD, 2013), las matemáticas son una herramienta crítica para las personas jóvenes ya que estos enfrentan asuntos y retos relacionados con esta en los ámbitos personal, ocupacional y social. Por esto, es importante tener un entendimiento del grado en el que las personas jóvenes están adecuadamente preparados para aplicar las matemáticas, para comprender asuntos importantes y resolver problemas significativos en su diario vivir. Una evaluación a la edad de 15 años provee una indicación temprana de como los individuos podrían responder en un futuro al diverso conjunto de situaciones que se encontrarán en sus vidas y que involucre el uso de las matemáticas.

La concepción de alfabetización matemática apoya la importancia de que los estudiantes desarrollen una fuerte comprensión de los conceptos de la matemática pura y los beneficios de estar comprometidos con la exploración del mundo abstracto de las matemáticas. El constructo de alfabetización matemática, según la definición de PISA, hace un remarcado énfasis en la necesidad de desarrollar la capacidad de los estudiantes, de utilizar las matemáticas de acuerdo con el contexto, para lo cual es importante que tengan ricas experiencias en sus clases de matemáticas (OECD, 2013).

El marco conceptual de la alfabetización matemática en PISA distingue entre grandes categorías de contenidos que son esenciales para la alfabetización en general, y los contenidos específicos de temas que son apropiados para los estudiantes de 15 años. La alfabetización matemática no es 
un atributo que un individuo tiene o no tiene, sino que está en continuo crecimiento, aunque sí se reconoce que algunos individuos son más alfabetizados matemáticamente que otros (OECD, 2013).

Para los propósitos de PISA, la alfabetización matemática se define como sigue:

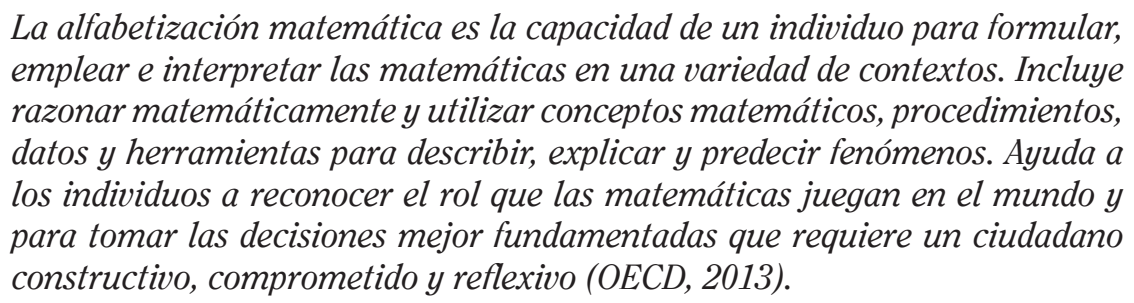

De esta manera, los resultados obtenidos a través de la evaluación PISA 2012 son de suma importancia para los países latinoamericanos, porque no se trata de evaluar lo aprendido puntualmente en los currículos educativos de cada país, sino de analizar la forma en que los estudiantes están en capacidad de aplicar lo aprendido en contextos que involucren la utilización de las matemáticas.

Para definir las variables que serán analizadas en este estudio, entonces, se recurrirá al mismo marco de referencia de PISA.

Los cuestionarios de contexto de la evaluación PISA 2012 incluyen una gran cantidad de ítems sobre las características de los estudiantes, extracción social de la familia, percepciones de los estudiantes, características de los centros educativos y la percepción de los directores de los centros educativos.

Algunos de los ítems fueron diseñados para ser utilizados en análisis como ítems singulares (por ejemplo el género). Sin embargo, la mayoría de los ítems de los cuestionarios fueron diseñados para ser combinados de cierta manera con el objetivo de medir constructos latentes que no pueden ser observados directamente (OECD, 2013).

Para estos ítems, fueron aplicados procedimientos de transformación o escalamiento para construir índices con sentido teórico y práctico.

Uno de los objetivos de PISA es el desarrollo de medidas comparables de las características de los estudiantes, las actitudes y las percepciones (OECD, 2013). La validación entre países de estos constructos es de particular importancia, ya que las mediciones derivadas de los cuestionarios son frecuentemente utilizadas para predecir diferencias en el rendimiento de los estudiantes, tanto dentro de cada país como entre países y, por ende, son fuentes potenciales de información relevante para las políticas educativas.

A continuación se describen brevemente los índices creados por los expertos de PISA para medir constructos que son de relevancia a la luz de la teoría sobre rendimiento educativo, y que serán utilizados en esta investigación (entre paréntesis se muestra el signo esperado en la estimación del modelo):

1. Posesiones de bienestar familiar (positivo): un índice que mide el bienestar familiar a través de algunos bienes presentes en el hogar, ya que se considera que medir el bienestar a través de estos bienes es una forma más estable que a través del ingreso. El estudiante debía responder si en su hogar había o no lo siguiente:

a. Una habitación solo para usted.

b. Conexión a Internet.

c. Reproductor de DVD.

d. Teléfonos celulares.

e. Televisores. 
f. Computadoras.

g. Automóvil.

h. Habitación con baño privado.

i. Tres ítems adicionales pero específicos de cada país.

2. Recursos educativos en el hogar (positivo): similar al anterior, pero midiendo artículos relevantes para el estudio en el hogar. Incluye lo siguiente:

a. Un escritorio o mesa para estudiar.

b. Un lugar tranquilo para estudiar.

c. Una computadora que puede usar para sus labores escolares.

d. Programas educativos para la computadora.

e. Libros de consulta para sus tareas escolares.

f. Libros de referencia técnica.

g. Un diccionario.

3. Posesiones culturales (positivo): de la misma forma que los anteriores, evalúa la presencia de bienes relacionados con el capital cultural en el hogar:

a. Libros de literatura clásica.

b. Libros de poesía.

c. Obras de arte.

4 Libros en el hogar (positivo): mide de manera directa la cantidad de libros en el hogar.

5. Nivel educativo más alto de los padres (positivo): es medido mediante años de educación de acuerdo con el ISCED (International Standard Classification of Education).

6. Estatus ocupacional más alto de los padres (positivo): es medido mediante el Índice ISEI (International Socio-Economic Index of Occupational Status).

7. Autoeficacia en matemáticas (positivo): ocho ítems fueron utilizados para medir este constructo, que se relaciona con el nivel de eficacia propia de cada estudiante para la resolución de problemas matemáticos. Dado cada ítem, el estudiante debía responder que tan seguro se siente al realizar las tareas matemáticas, en una escala que va de muy seguro, seguro, no muy seguro a nada seguro. Dos ejemplos de estos ítems son los siguientes:

a. Calcular cuánto más barato vale un televisor con un $30 \%$ de descuento.

b. Resolver una ecuación como esta: $2(\mathrm{x}+3)=(\mathrm{x}+3)(\mathrm{x}-3)$.

8. Ansiedad en matemáticas (negativo): cinco ítems fueron utilizados para medir este constructo, que se relaciona con el nivel de ansiedad con que el estudiante aborda situaciones que involucren el uso de matemáticas. La escala de respuesta es: totalmente de acuerdo, de acuerdo, en desacuerdo, totalmente en desacuerdo. Dos ejemplos de estos ítems son los siguientes: 
a. Me pongo muy nervioso cuando me enfrento a un problema matemático.

b. Me preocupa sacar bajas notas en matemática.

9. Familiaridad con conceptos matemáticos (positivo): trece ítems miden la familiaridad auto percibida del estudiante a algunos conceptos matemáticos como la función exponencial, función cuadrática, divisor, número racional, coseno, y otros. La escala de respuesta es: nunca oí hablar de eso, oí hablar de eso una o dos veces, he oído hablar de eso algunas veces, he oído hablar de eso frecuentemente, lo conozco bien y entiendo el concepto.

10. Motivación instrumental hacia las matemáticas (positivo): cuatro ítems fueron utilizados para medir este constructo, que se relaciona con la importancia que tiene para el estudiante el estudio de las matemáticas. La escala de respuesta es: totalmente de acuerdo, de acuerdo, en desacuerdo, totalmente en desacuerdo. Dos ejemplos de estos ítems son los siguientes:

a. Hacer un esfuerzo en matemáticas vale la pena porque esto me ayudará en el trabajo que quiero conseguir en el futuro.

b. Matemáticas es una materia importante para mí porque la necesito para lo que quiero estudiar en el futuro.

11. Interés en las matemáticas (positivo): cuatro ítems fueron utilizados para medir este constructo, que se relaciona el interés propio y el gusto que tiene el estudiante hacia esta materia. La escala de respuesta es: totalmente de acuerdo, de acuerdo, en desacuerdo, totalmente en desacuerdo. Dos ejemplos de estos ítems son los siguientes:

a. Espero con ansias mis lecciones de matemáticas.

b. Practico la matemática porque me gusta.

12. Apoyo del profesor de matemáticas (positivo): cuatro ítems fueron utilizados para medir este constructo. La escala de respuesta es: totalmente de acuerdo, de acuerdo, en desacuerdo, totalmente en desacuerdo. Dos ejemplos de estos ítems son los siguientes:

a. Mi profesor nos da ayuda extra cuando la necesitamos.

b. Mi profesor da oportunidad a los estudiantes para que expresen sus opiniones.

13. Auto concepto en matemáticas (positivo): cuatro ítems fueron utilizados para medir este constructo, en el que el estudiante se auto califica en cuanto a sus capacidades matemáticas. En este caso, la escala de respuestas se basan en qué tan probable es que el estudiante tenga estos pensamientos o sentimientos ante algunas situaciones. Dos ejemplos de estos ítems son los siguientes:

a. No soy bueno para resolver problemas de matemática.

b. A veces los temas de la lección son demasiado difíciles.

14. Relaciones estudiante profesor (positivo): cuatro ítems fueron utilizados para medir las relaciones entre el estudiante con los profesores de su centro educativo. La escala de respuesta es: totalmente de acuerdo, de acuerdo, en desacuerdo, totalmente en desacuerdo. Dos ejemplos de estos ítems son los siguientes: 
a. La mayoría de los profesores se interesan en el bienestar de los estudiantes.

b. Los estudiantes se llevan bien con la mayoría de los profesores.

15. Actitud hacia el centro educativo (positivo): cuatro ítems fueron utilizados para medir este constructo, que se relaciona con la actitud del estudiante hacia el centro de enseñanza al que asiste. La escala de respuesta es: totalmente de acuerdo, de acuerdo, en desacuerdo, totalmente en desacuerdo. Dos ejemplos de estos ítems son los siguientes:

a. El colegio ha sido una pérdida de tiempo.

b. El colegio me ha enseñado cosas que pueden ser útiles en un trabajo.

16. Sentido de pertenencia al centro educativo (positivo): nueve ítems fueron utilizados para medir este constructo, que se relaciona con el sentido propio del estudiante de pertenencia a su colegio. La escala de respuesta es: totalmente de acuerdo, de acuerdo, en desacuerdo, totalmente en desacuerdo. Dos ejemplos de estos ítems son los siguientes:

a. En el colegio me siento incómodo y fuera de lugar.

b. En el colegio hago amigos fácilmente.

Además de los dieciséis índices explicados, se toma en cuenta como variables las siguientes:

17. Sexo.

18. Asistencia a educación preescolar (un año o más).

19. Repitencia de años educativos en primaria.

20. Repitencia de años educativos en secundaria baja.

21. Sector del centro educativo (público o privado). Esta es la única variable del cuestionario de contexto del colegio que será incorporado en el estudio. 
Para estas últimas variables, el cuadro 4 muestra la proporción de estudiantes que tienen dichas características. Por ejemplo, solo en Argentina, México y Uruguay, más del 70\% los estudiantes que participaron de la prueba PISA 2012 asistieron a la educación preescolar por un año o más, mientras que en Colombia solo un 34\% lo hicieron. México, Costa Rica, Brasil y Uruguay tienen la mayor proporción de estudiantes asistiendo a educación pública en sus sistemas educativos, por encima del 80\%; además, Chile y México muestran la menor proporción de estudiantes que han repetido años educativos, tanto en primaria como en secundaria, mientras que Colombia y en Costa

CUADRO 4

PORCENTAJE DE ESTUDIANTES QUE PRESENTAN LA CARACTERÍSTICA POR PAÍS

\begin{tabular}{lcccccccc}
\hline Variable & Argentina & Brasil & Chile & Colombia & $\begin{array}{c}\text { Costa } \\
\text { Rica }\end{array}$ & México & Perú & Uruguay \\
\hline Mujer & 52,7 & 53,0 & 51,2 & 53,0 & 53,5 & 51,9 & 51,7 & 53,2 \\
Asistió a Preescolar & 72,9 & 45,4 & 41,0 & 34,1 & 44,7 & 72,9 & 61,0 & 70,4 \\
más de un año & & & & & & & & \\
Asiste a colegio público & 63,5 & 85,7 & 27,7 & 79,2 & 85,9 & 87,7 & 78,8 & 83,5 \\
Repitió en primaria & 17,3 & 23,4 & 9,2 & 20,0 & 15,1 & 9,2 & 18,9 & 21,4 \\
Repitió en secundaria & 22,7 & 20,8 & 5,4 & 27,0 & 24,1 & 2,4 & 12,6 & 27,1 \\
\hline
\end{tabular}

Fuente: Elaboración propia con datos de la evaluación PISA 2012. 


\section{METODOLOGÍA}

\section{Construcción de la muestra utilizada por PISA}

La muestra de PISA está diseñada sobre una población de estudiantes con edades entre los 15 años $y$ tres meses (completos) y 16 años y dos meses (completos) que asisten a las instituciones educativas oficiales y se encuentran cursando un grado equivalente al séptimo o superior para todos los países participantes. Por conveniencia, se hace referencia a la población como estudiantes de 15 años. ${ }^{4}$

El diseño de la muestra para estudios educativos normalmente no se basa en un muestreo aleatorio simple sobre la población objetivo. En su lugar, se utiliza un muestreo en dos etapas: en la primera una muestra de centros educativos es seleccionada de una lista completa de los centros educativos que incluyen a la población de estudiantes de interés. En el caso de PISA, todos los centros educativos son seleccionados con una probabilidad que es proporcional a su tamaño. Para las tasas de participación, PISA maneja como estándar una tasa de mínima respuesta de los centros educativos del 85\% para disminuir el sesgo por no respuesta.

En la segunda etapa, se selecciona aleatoriamente una muestra de estudiantes para los centros educativos seleccionados. En los estudios realizados por PISA, se elige a un mínimo de 30 estudiantes en edad de 15 años para cada centro educativo participante.

La cobertura bruta de jóvenes de 15 años de cada país (estén o no en el sistema educativo) se muestra en el cuadro 4. En promedio, para Latinoamérica la muestra de estudiantes únicamente representa al 68\% de la población de jóvenes de 15 años que reside en estos 8 países (ver cuadro 5).

\section{CUADRO 5}

INFORMACIÓN DE LA POBLACIÓN Y LA MUESTRA DE ESTUDIANTES LATINOAMERICANOS PARTICIPANTES EN LA EVALUACIÓN PISA 2012

\begin{tabular}{lrrrrrr}
\hline & Población de 15 años de edad & & \multicolumn{2}{c}{ Tamaño de muestra } & Cobertura de la po- \\
\cline { 2 - 3 } País & \multicolumn{1}{c}{ Total } & Matriculada & & Sin ponderar & Ponderado & blación de 15 años \\
\hline Chile & 274.803 & 252.733 & & 6.857 & 229.199 & 0,834 \\
Argentina & 684.879 & 637.603 & & 5.908 & 545.942 & 0,797 \\
Uruguay & 54.638 & 46.442 & & 5.315 & 39.771 & 0,728 \\
Peru & 584.294 & 508.969 & 6.035 & 419.945 & 0,719 \\
Brasil & 3.574 .928 & 2.786 .064 & 20.091 & 2.470 .804 & 0,691 \\
Colombia & 889.729 & 620.422 & 11.173 & 560.805 & 0,630 \\
Mexico & 2.114 .745 & 1.472 .875 & 33.806 & 1.326 .025 & 0,627 \\
Costa Rica & 81.489 & 64.326 & 4.602 & 40.384 & 0,496 \\
\hline
\end{tabular}

Fuente: Elaboración propia con datos de la evaluación PISA 2012.

4 El hecho de que la muestra esté basada en estudiantes de 15 años garantiza que solo se considera lo que un joven de 15 años sabe y puede aplicar a esa edad en todo el mundo. Esta evaluación toma en cuenta que hay países con un elevado nivel de rezago educativo; en otras palabras, las diferencias en rendimiento pueden darse debido a una menor calidad educativa producto de las diferencias en contenido curricular de cada país, y debido al hecho de que hay países cuyos estudiantes están más rezagados a la edad de 15 años. 
Sin embargo, en algunos países, el dato es aún más bajo, siendo el caso más grave en Costa Rica, donde el índice de cobertura es de 0,496, la más baja de los 64 países participantes en PISA 2012. Esto quiere decir que la muestra solo es representativa de un 50\% de todos los jóvenes de 15 años que viven en dicho país centroamericano. El nivel de exclusión (porcentaje complementario) de 50,4\% no solo se explica a partir de la población de 15 años que no está cubierta por el sistema educativo, sino que también incluye el considerable número de jóvenes costarricenses que, al tener adecuaciones curriculares, no formaron parte del marco muestral de PISA en esta oportunidad, así como los jóvenes que están en el sistema de educación abierta.

De acuerdo con Montero (2013), es de esperar que estos grupos juveniles excluidos del marco muestral tuvieran un desempeño relativamente menor en estas pruebas, comparado con el grupo que sí se muestreó, dado que se puede argumentar, en general, que tienen acceso a menos oportunidades educativas. De esta forma, entre más bajo sea el índice de cobertura, más sobreestimado estará el desempeño de los jóvenes, es decir, es probable que si un país como Costa Rica lograra que la cobertura de estudiantes participantes en PISA fuera mayor (similar a la de Chile, por ejemplo), su rendimiento promedio sería aún más bajo.

De hecho, recientemente fueron publicados los resultados de PISA 2015, que mostraron reducciones en los promedios de matemáticas, lectura y ciencias, pero estas reducciones eran previsibles, ya que la cobertura de la muestra pasó de 50\% a 63\% del año 2012 al 2015. En este sentido, mientras el país continúe por la senda de atraer más estudiantes al sistema educativo, es esperable no ver mejoras en futuras evaluaciones de PISA, hasta que alcancemos un nivel de equilibrio en la cobertura de la educación secundaria.

\section{Modelo multinivel}

Una forma usual de encontrar los datos en las ciencias sociales y del comportamiento es en estructuras jerárquicas, donde los sujetos se encuentran agrupados en uno o más niveles jerárquicos.

Los modelos multinivel son útiles porque permiten tratar estadísticamente la variación originada por las diferencias individuales como el contexto, lo cual no puede ser incorporado en los modelos de regresión lineal clásicos, típicamente estimados mediante mínimos cuadrados ordinarios, ya que solo permiten incorporar por separado las variables del individuo o las variables del contexto ${ }^{5}$.

En este caso, para cada macro nivel o nivel de contexto es estimada una regresión lineal en el micro nivel. Con respecto a los datos que son utilizados en esta investigación, los sujetos o unidades individuales son estudiantes en edad de 15 años, los cuales se agrupan en sus respectivos centros educativos, que a su vez se encuentran anidados en cada país de la región latinoamericana. Esta es una estructura jerárquica en tres niveles: un primer nivel donde están los estudiantes, un segundo nivel donde se ubican los centros educativos que contienen a estos estudiantes y que toma en cuenta las variaciones en cada centro educativo, $y$ un tercer nivel representado por los países donde se reúnen los centros educativos y que considera las diferencias existentes en cada país.

Los modelos multinivel son un caso particular de los modelos mixtos, ya que presentan la ventaja de que permiten incluir características tanto de las unidades de estudio como de los grupos

5 Cuando únicamente se toman en cuenta variables del individuo se está en presencia de la falacia atomística. Cuando solo se incorporan variables del contexto se comete lo que se conoce como falacia ecológica. 
a los que éstas pertenecen ${ }^{6}$; permiten, además, tomar en cuenta la correlación intraclase de los conglomerados y la estimación de la variabilidad que poseen las relaciones estimadas a nivel individual dependiendo del conglomerado?.

En un modelo mixto pueden ser estimados tanto coeficientes fijos como coeficientes aleatorios. Los coeficientes fijos incluyen las medias generales de los efectos estimados para las variables individuales. Los coeficientes aleatorios se estiman mediante la matriz de variancias y covarianzas de las medias generales.

En esta investigación será estimada una regresión multinivel con coeficientes fijos y un coeficiente aleatorio. Todas las variables explicadas en la II parte serán introducidas al modelo como coeficientes fijos y, adicionalmente, será evaluada la hipótesis de que la varianza con respecto a la asistencia a la educación preescolar varía de acuerdo al contexto, es decir, que existen diferencias tanto en los centros educativos como en los países de la forma en que actúa el efecto de haber asistido a la educación preescolar y, por lo tanto, esto debe ser modelado mediante la estimación del coeficiente aleatorio en los macro niveles.

La representación básica de un modelo de tres niveles es la siguiente:

$$
\mathrm{y}_{i j k}=\beta_{0 j k}+\beta_{i j k} \mathrm{X}_{i j k}+\epsilon_{i j k}
$$

Donde el subíndice $\mathrm{k}$ representa el nivel $3^{\circ}$ de los países, el subíndice j representa el nivel $2^{\circ}$ de los centros educativos y el subíndice i es utilizado para el nivel $1^{\circ}$ de los estudiantes. El modelo a estimar presenta tanto interceptos aleatorios $\left(\beta_{0 j k}\right)$ como pendientes aleatorias $\left(\beta_{i j k}\right)$.

Los niveles 2 y 3 de este modelo se expresan como:

$$
\begin{gathered}
\text { Nivel 2: } \beta_{0 j k}=\gamma_{00 k}+U_{0 j k} \\
\beta_{1 j k}=\gamma_{10 k}+U_{1 j k} \\
\text { Nivel 3: } \gamma_{00 k}=\delta_{000}+V_{00 k} \\
\gamma_{10 k}=\delta_{100}+V_{10 k}
\end{gathered}
$$

La ecuación extendida para este modelo se expresa en forma ampliada como sigue:

$$
y_{i j k}=\delta_{000}+V_{00 k}+U_{0 j k}\left(\delta_{100}+V_{10 k}+U_{1 j k}\right) X_{i j k}+\epsilon_{i j k}
$$

6 Los modelos de regresión lineal clásico y mixto son casos particulares de los modelos lineales mixtos generalizados, aunque con diferencias en los supuestos de cada modelo. En el modelo de regresión lineal clásico, es necesario asumir homogeneidad en la variancia e independencia de las observaciones. En el modelo lineal mixto, se mantiene el supuesto de la homogeneidad de la variancia; no obstante, se suaviza el supuesto de independencia de las observaciones, para tomar en cuenta la dependencia entre ellas. Los modelos mixtos generalizados permiten el análisis de variables no métricas ni normales y no es necesario asumir homogeneidad de las variancias ni independencia de las observaciones.

$7 \quad$ La correlación intraclase mide la homogeneidad interna de los grupos, en otras palabras, la similitud de las unidades de primer nivel $y$ las diferencias entre las unidades de niveles superiores. 
Variables e imputación de datos faltantes

Como fue explicado en la sección anterior, serán introducidas 21 variables en el modelo, 20 de las cuales provienen del cuestionario aplicado a los estudiantes y una que corresponde al cuestionario completado por los directores escolares.

La mayoría de estas variables corresponden a índices previamente calculados por los expertos de PISA utilizando la teoría de respuesta al ítem y modelos de Rasch. Estos índices son computados para tener una media de cero y una desviación estándar de uno para los países miembros de la OECD.

Sin embargo, debido a que el interés de este estudio es poder comparar apropiadamente las magnitudes de los efectos de cada variable, es necesario estandarizarlas antes de introducirlas al modelo. En este caso, los trece índices (que corresponden a variables continuas) fueron estandarizados ${ }^{8}$.

Para las restantes 8 variables, su codificación es la siguiente:

- Sexo: 1 si es mujer 0 si es hombre.

- Asistió a preescolar: 1 si asistió uno o más años, 0 si asistió menos de un año o nunca asistió.

- $\quad$ Repitencia en primaria: 1 si perdió algún año en primaria 0 en otro caso.

- Repitencia en secundaria: 1 si perdió algún año en secundaria baja 0 en otro caso.

- $\quad$ Libros en el hogar: variable categórica de seis categorías: de 0 a 10 libros; de 11 a 25 libros; de 26 a 100 libros; de 101 a 200 libros; de 201 a 500; más de 500.

- Nivel educativo más alto de los padres: variable categórica con las siguientes categorías: ninguno; primaria; secundaria baja; secundaria alta; técnico, profesorado o diplomado; bachillerato universitario, licenciatura o posgrado.

- Estatus ocupacional más alto de los padres: será tratado como variable continua, ya que varía desde un mínimo de 16 y hasta un máximo de 90, de acuerdo con el estatus del tipo de actividad económica, por lo que también fue estandarizada.

- $\quad$ Sector del colegio: 1 si es público 0 si es privado.

Además, la presencia de valores faltantes es muy común en la recolección de datos en las ciencias sociales, y el programa PISA no escapa a esto. Sin embargo, la evaluación PISA del año 2012 tuvo la particularidad de que por primera vez fue aplicado un diseño con rotación de cuestionario. Este tipo de diseño es utilizado cuando se desea indagar mucha más información de relevancia para la toma de decisiones (OECD, 2012).

Así, para lograr obtener toda la información necesaria del cuestionario y prevenir un incremento en los datos faltantes, en la evaluación del 2012, fue introducido el diseño con rotación de cuestionario, únicamente en el cuestionario de contexto de los estudiantes.

Esta rotación consiste en distribuir todos los paquetes temáticos del universo total de preguntas de dicho cuestionario en distintos formularios con varias combinaciones de estos paquetes temáticos en cada uno, por lo que en cada formulario se indaga un número menor de preguntas, pero al tomarlos todos juntos se garantiza la respuesta por parte de cada país de todos los ítems de la batería completa de preguntas. 
Fueron formados tres formularios para la evaluación del 2012, donde cada formulario indaga dos terceras partes de la batería completa de preguntas, aunque todos incluyen una parte común de 25 ítems sobre la información básica de los estudiantes (como género, grado cursado e información sobre su hogar y su familia). De esta manera, se logra obtener un 33\% más de información (OECD, 2012).

Estos formularios son rotados aleatoriamente entre todos los estudiantes de cada centro educativo, lo que garantiza que el proceso de datos omitidos se genera en forma completamente aleatoria (Missing completely at Random, MCAR), ya que la distribución de los valores observados no depende del patrón de comportamiento de los registros sin información.

Esta rotación aleatoria de los cuestionarios permite realizar el supuesto de distribución de datos faltantes como MCAR o como MAR, que es requerido para la aplicación de distintas técnicas de imputación sobre los valores faltantes.

De esta manera, en este trabajo será aplicada la técnica de imputación de datos faltantes predicitive mean matching bajo el supuesto de que los datos faltantes se distribuyen en forma completamente aleatoria. La imputación se hará con el paquete de R "mice”: Multivariate Imputation by Chained Equations (van Buuren y Groothuis-Oudshoorn, 2011).

\section{RESULTADOS}

La modelación multinivel es necesaria cuando existe dependencia de las unidades del primer nivel en relación con los conglomerados en los que se agrupan. En los datos analizados para la región latinoamericana, es posible calcular el coeficiente de correlación intraclase (CCI) tanto para el segundo (centros educativos) como para el tercer nivel (países).

Para el segundo nivel, el CCI es de 0,468, bastante alto, y evidencia una alta dependencia de la variabilidad de los resultados académicos de acuerdo con la agrupación en los centros educativos. Este resultado dice mucho del caso de América Latina, ya que podría ser evidencia de las grandes desigualdades que existen en los centros educativos de la región y que terminan incidiendo en la distribución de los resultados educativos.

En el tercer nivel, el CCI es de 0,074, que si bien es más bajo, también muestra que existe cierta variabilidad que es explicada por la dependencia de las unidades entre los países.

Aunque la intención del modelo de tres niveles es estimarlo con un coeficiente aleatorio en el segundo y tercer nivel, a continuación se presentan los criterios de información de Akaike y Bayesiano de este modelo y otras tres alternativas, que excluyen alguno o ambos de los coeficientes aleatorios ${ }^{9}$.

9 Se trata de criterios de información sobre el ajuste de distintas especificaciones de un modelo para el mismo set de datos. 
CUADRO 6

RESULTADOS DEL CRITERIO E INFORMACIÓN DE AKAIKE Y BAYESIANO PARA DISTINTOS MODELOS

\begin{tabular}{|c|c|c|c|c|c|}
\hline \multirow{2}{*}{ Modelo } & \multicolumn{3}{|c|}{ Especificación de los Coeficientes } & \multirow{2}{*}{ AIC } & \multirow{2}{*}{ BIC } \\
\hline & Fijos & Aleatorios $\left(2^{\circ}\right.$ nivel $)$ & Aleatorios $\left(3^{\circ}\right.$ nivel $)$ & & \\
\hline Modelo nulo & No & No & No & 212.985 & 213.022 \\
\hline Modelo 1 & Sí & No & No & 136.160 & 136.388 \\
\hline Modelo 2 & Sí & Sí & No & 136.158 & 136.405 \\
\hline Modelo 3 & Sí & No & Sí & 136.101 & 136.363 \\
\hline Modelo 4 & Sí & Sí & Sí & 136.092 & 136.357 \\
\hline
\end{tabular}

Fuente: Elaboración propia con datos de la evaluación PISA 2012.

Según se presenta en el cuadro 6, el modelo que muestra los valores más bajos de ambos criterios para comprar entre modelos es el 4, que incluye el coeficiente aleatorio en la variable de preescolar tanto en el segundo como en el tercer nivel, lo que refuerza la hipótesis de que es correcto modelar el efecto aleatorio de la variable de asistencia a la educación preescolar.

De esta manera, se procede con el modelo 4. A continuación, en el cuadro 7 se muestran los resultados de las estimaciones de este modelo para la región latinoamericana; todos los coeficientes se encuentran estandarizados para su correcta comparación ${ }^{10}$ :

10 A este modelo le fueron realizadas las pruebas necesarias para verificar el cumplimiento de los supuestos de normalidad en los errores y de no multicolinealidad. 
CUADRO 7

RESULTADOS DEL MODELO DE TRES NIVELES CON COEFICIENTES ALEATORIOS EN LOS NIVELES 2 Y 3

\begin{tabular}{lcccccc}
\hline Variable & Estimación & Error estándar & $\mathrm{t}$-value & p-value & \multicolumn{2}{c}{ Parámetros aleatorios } \\
\hline (Intercepto) & 0,222 & 0,084 & 2,65 & 0,008 & Nivel 3: País & \\
Mujer & $-0,202$ & 0,005 & $-39,32$ & 0,000 & Desv Est(Preescolar) & 0,064 \\
Preescolar & 0,070 & 0,024 & 2,95 & 0,003 & Desv Est(constante) & 0,230 \\
Público & $-0,411$ & 0,020 & $-21,00$ & 0,000 & Nivel 2: Colegios & \\
Repitencia primaria & $-0,410$ & 0,010 & $-39,95$ & 0,000 & Desv Est(Preescolar) & 0,054 \\
Repitencia secundaria & $-0,214$ & 0,011 & $-19,54$ & 0,000 & Desv Est(constante) & 0,404 \\
Libros & 0,045 & 0,003 & 17,63 & 0,000 & & \\
Educación padres & 0,009 & 0,002 & 49,73 & 0,000 & Desv Est Residual & 0,621 \\
Estatus ocupacional & 0,003 & 0,000 & 16,96 & 0,000 & & \\
Bienestar & 0,003 & 0,004 & 0,00 & 0,407 & Pseudo R2 & 0,416 \\
Recursos educativos & $-0,007$ & 0,003 & $-22,09$ & 0,027 & & \\
Autoeficacia & 0,114 & 0,003 & 35,38 & 0,000 & & \\
Ansiedad & $-0,130$ & 0,003 & $-42,17$ & 0,000 & & \\
Actitud centro educativo & 0,074 & 0,003 & 24,14 & 0,000 & & \\
Sentido pertenencia & $-0,045$ & 0,003 & $-14,35$ & 0,000 & & \\
Posesiones culturales & $-0,025$ & 0,003 & $-84,64$ & 0,003 & & \\
Conceptos matemáticos & 0,116 & 0,003 & 38,27 & 0,000 & & \\
Motiv instrumental & 0,015 & 0,003 & 4,40 & 0,000 & & \\
Interés en matemáticas & $-0,120$ & 0,004 & $-29,68$ & 0,000 & & \\
Apoyo docente & $-0,040$ & 0,003 & $-13,50$ & 0,000 & & \\
Autoconcepto & 0,185 & 0,004 & 47,59 & 0,000 & & \\
Rel. Estud.-Prof & $-0,054$ & 0,003 & $-17,19$ & 0,000 & & \\
\hline
\end{tabular}

Fuente: Elaboración propia con datos de la evaluación PISA 2012.

Notas: Desv Est= Desviación Estándar. Los coeficientes no significativos al 99\% de confianza se muestran en color rojo. Los coeficientes estadísticamente significativas y mayores a 0,1 en valor absoluto se muestran sombreados de color naranja.

Lo primero que se destaca es el recuadro de la parte superior derecha, que muestra los resultados de la parte aleatoria del modelo. En este se aprecia que existe una variabilidad no despreciable alrededor de las diferencias en la asistencia a la educación preescolar en los niveles 2 y 3 , es decir, el efecto del haber asistido a la educación preescolar es distinto tanto entre centros educativos como entre países.

Los resultados se muestran en términos de la desviación estándar de la variable dependiente que, en este caso, es el resultado en la prueba de matemáticas. Para Latinoamérica, una desviación estándar de los resultados de los estudiantes en la prueba de matemáticas equivale a 80 puntos, por lo que los efectos aleatorios del haber asistido a la educación preescolar más de un año varían hasta en 15 puntos del puntaje final de la prueba en el $99 \%$ de la muestra.

Además, para este modelo fue estimada una aproximación a la medida de bondad de ajuste llamada R-cuadrado, que es muy utilizada en los modelos de regresión que no incorporan estructuras multinivel. En este caso, fue estimado un pseudo R-cuadrado, ya que únicamente incluye el efecto de la parte fija del modelo. Para este modelo, el pseudo R-cuadrado es de un 0,41, es decir, aproximadamente un $41 \%$ de la variabilidad en los resultados de los estudiantes latinoamericanos en la prueba de alfabetización matemática se explica con la inclusión de las variables de la parte fija. 
Por otra parte, en la parte fija del modelo todas las variables a excepción de dos resultan estadísticamente significativas al 99\% de confianza. Los constructos de posesiones de bienestar familiar $y$ recursos educativos en el hogar son las únicas dos variables que no muestran una asociación importante con el rendimiento educativo en matemáticas, muy posiblemente por su alta correlación con variables que miden un factor similar sobre el estatus socioeconómico del hogar, como la educación de los padres o el estatus ocupacional.

Casi la totalidad de los coeficientes muestran el signo apropiado de acuerdo con lo esperado. Las variables que muestran signos negativos también muestran este comportamiento, por ejemplo, las mujeres puntúan menos en promedio que los hombres; los estudiantes que asisten a colegios públicos o han repetido años escolares también obtienen menores resultados que los alumnos de colegios privados y que nunca han repetido. Los estudiantes que se muestran más ansiosos al momento de aplicar las matemáticas muestran menores rendimientos.

Hay dos variables que también muestran signos negativos con resultados interesantes. Los estudiantes que sienten que no pertenecen a su centro educativo o no se sienten identificados con el mismo (especialmente porque les es más difícil relacionarse con otros y entablar amistades) muestran rendimientos más altos que los estudiantes que tienen un sentido de pertenencia mayor. Una posible hipótesis para esto es que típicamente se ha concebido que a algunos de los estudiantes más exitosos académicamente se les dificulta la socialización y el integrarse a un grupo de personas, lo que podría explicar este resultado.

Además, los estudiantes que no reciben apoyo de sus profesores también obtienen mejores calificaciones. Este resultado tiene sentido bajo la hipótesis de que los estudiantes que reciben apoyo de sus profesores son los que realmente lo necesitan, porque se les dificulta más comprender los contenidos curriculares, mientras que los estudiantes que captan con mayor facilidad el material recibido en las lecciones escolares no requerirían de esta ayuda.

Tres resultados que sí son contra intuitivos son el signo negativo en los índices de posesiones culturales $y$ de recursos educativos en el hogar, y el constructo de interés en las matemáticas, ya que se esperaba un signo positivo en estos tres casos. Estos resultados podrían deberse a una relación espuria con otras variables relevantes al modelo, pero que no se encuentran en él o a una incorrecta medición de dichos constructos en los cuestionarios y escalas de PISA, lo cual debiera ser revisado en futuras investigaciones.

Dado que todas las variables se encuentran estandarizadas, es posible comparar los valores resultantes de los coeficientes para conocer cuáles variables muestran mayor asociación con las diferencias en los rendimientos. Para esto, en el cuadro anterior fueron resaltados los coeficientes estimados mayores a 0,10 en valor absoluto, ya que esta sería una asociación considerablemente alta con el puntaje en la prueba PISA.

Además de los coeficientes asociados a las variables de control (género, sector, repitencia), existen cuatro constructos que resultan sumamente importantes: la autoeficacia en matemáticas, la ansiedad hacia las matemáticas, la familiaridad con los conceptos matemáticos y el autoconcepto en matemáticas.

Lo primero que se debe notar es que estos cuatro factores son intrínsecos al estudiante, es decir, son factores personales que se encuentran relacionados con la actitud propia hacia las matemáticas y de su propia valoración en cuanto a sus capacidades para utilizar correctamente las matemáticas como una herramienta útil en diversas situaciones.

Sin embargo, todos estos resultados provienen del análisis de la muestra de estudiantes de los ocho países latinoamericanos como un todo. Resulta interesante conocer si estos mismos resultados se mantienen al realizar un análisis más detallado en cada país, o si las relaciones cambian (por ejemplo, de la estimación anterior se sabe que el efecto de la asistencia a la educación preescolar varía con respecto al país que se está analizando).

Por esta razón, este mismo modelo fue estimado para cada país, pero ahora se trata de un modelo de dos niveles (estudiantes y centros educativos). El cuadro 8 muestra estos resultados. 
CUADRO 8

COEFICIENTES ESTIMADOS DE LA REGRESIÓN DE DOS NIVELES CON COEFICIENTE ALEATORIO PARA CADA PAÍS DE LATINOAMERICA

\begin{tabular}{|c|c|c|c|c|c|c|c|c|}
\hline $\begin{array}{l}\text { Parámetros aleatorios del } \\
\text { Nivel 2: Colegios }\end{array}$ & Argentina & Brasil & Chile & Colombia & Costa Rica & México & Perú & Uruguay \\
\hline Desv Est(Preescolar) & 0,113 & 0,033 & 0,027 & 0,010 & 0,121 & 0,087 & 0,101 & 0,101 \\
\hline Puntaje en la prueba & 9,1 & 2,6 & 2,4 & 0,8 & 8,1 & 6,4 & 8,4 & 8,9 \\
\hline Desv Est(constante) & 0,396 & 0,402 & 0,380 & 0,395 & 0,343 & 0,434 & 0,447 & 0,287 \\
\hline Varianza Residual & 0,591 & 0,648 & 0,556 & 0,576 & 0,632 & 0,675 & 0,592 & 0,579 \\
\hline Pseudo R2 & 0,475 & 0,419 & 0,556 & 0,445 & 0,452 & 0,357 & 0,483 & 0,552 \\
\hline Variable & & & Coefic & ntes estand & rizados estir & ados & & \\
\hline (Intercepto) & 0,217 & 0,817 & $-0,123$ & 0,250 & 0,430 & 0,060 & 0,256 & 0,310 \\
\hline Mujer & $-0,175$ & $-0,260$ & $-0,236$ & $-0,315$ & $-0,312$ & $-0,159$ & $-0,271$ & $-0,166$ \\
\hline Preescolar & 0,128 & 0,127 & 0,029 & $-0,011$ & $-0,010$ & 0,032 & 0,074 & 0,129 \\
\hline Público & $-0,493$ & $-0,830$ & $-0,419$ & $-0,250$ & $-0,423$ & $-0,173$ & $-0,422$ & $-0,492$ \\
\hline Repitencia primaria & $-0,362$ & $-0,475$ & $-0,398$ & $-0,308$ & $-0,352$ & $-0,446$ & $-0,318$ & $-0,497$ \\
\hline Repitencia secundaria & $-0,199$ & $-0,259$ & $-0,281$ & $-0,190$ & $-0,261$ & $-0,194$ & $-0,173$ & $-0,288$ \\
\hline Libros & 0,052 & 0,024 & 0,074 & 0,049 & 0,046 & 0,034 & 0,067 & 0,066 \\
\hline Educación padres & 0,007 & 0,017 & 0,013 & 0,021 & 0,019 & 0,002 & 0,014 & $-0,009$ \\
\hline Estatus ocupacional & 0,003 & 0,003 & 0,002 & 0,002 & 0,002 & 0,003 & 0,002 & 0,005 \\
\hline Bienestar & $-0,000$ & $-0,033$ & 0,010 & 0,119 & 0,080 & 0,005 & 0,018 & $-0,039$ \\
\hline Recursos educativos & $-0,008$ & 0,022 & $-0,042$ & $-0,020$ & $-0,024$ & $-0,013$ & 0,021 & $-0,011$ \\
\hline Autoeficacia & 0,140 & 0,099 & 0,084 & 0,046 & 0,046 & 0,146 & 0,089 & 0,129 \\
\hline Ansiedad & $-0,177$ & $-0,132$ & $-0,089$ & $-0,132$ & $-0,091$ & $-0,151$ & $-0,099$ & $-0,112$ \\
\hline Actitud centro educativo & 0,055 & 0,058 & 0,006 & 0,061 & 0,065 & 0,116 & 0,067 & 0,022 \\
\hline Sentido pertenencia & $-0,011$ & $-0,041$ & $-0,042$ & $-0,006$ & $-0,052$ & $-0,059$ & $-0,051$ & $-0,037$ \\
\hline Posesiones culturales & 0,013 & $-0,039$ & 0,010 & $-0,036$ & $-0,019$ & $-0,018$ & $-0,120$ & 0,006 \\
\hline Conceptos matemáticos & 0,091 & 0,076 & 0,176 & 0,175 & 0,228 & 0,103 & 0,176 & 0,156 \\
\hline Motiv instrumental & 0,055 & $-0,003$ & 0,038 & 0,007 & $-0,060$ & 0,021 & 0,023 & 0,001 \\
\hline Interés en matemáticas & $-0,086$ & $-0,083$ & $-0,115$ & $-0,140$ & $-0,095$ & $-0,140$ & $-0,175$ & $-0,124$ \\
\hline Apoyo docente & $-0,026$ & $-0,036$ & $-0,031$ & $-0,039$ & $-0,085$ & $-0,050$ & $-0,008$ & $-0,047$ \\
\hline Autoconcepto & 0,115 & 0,099 & 0,203 & 0,238 & 0,195 & 0,225 & 0,253 & 0,180 \\
\hline Rel. Estud.-Prof & $-0,095$ & $-0,006$ & $-0,017$ & $-0,081$ & $-0,041$ & $-0,078$ & $-0,083$ & $-0,022$ \\
\hline
\end{tabular}

Fuente: Elaboración propia con datos de la evaluación PISA 2012.

Notas: Desv Est= Desviación Estándar. Los coeficientes no significativos al 99\% de confianza se muestran en color rojo. Los coeficientes estadísticamente significativos y mayores a 0,1 en valor absoluto se muestran sombreados de color naranja. El puntaje en la prueba muestra la cantidad de puntos en la prueba de PISA de matemáticas que son explicados por la variabilidad aleatoria de la variable de Preescolar. 
El cuadro anterior indica el mismo pseudo R-cuadrado estimado para cada modelo-país, que varía desde un 35\% en México hasta un 56\% en el caso chileno.

Para comenzar se analiza primero la parte aleatoria del modelo. Las diferencias en los resultados explicados por haber asistido a la educación preescolar más de un año son diferentes para todos los países. Dados estos resultados, es posible dividir a estos 8 países en cuatro grupos, de acuerdo con la importancia del tipo de efecto de la variable de asistencia a educación preescolar.

El primer grupo consta de tres países (Argentina, Brasil y Uruguay) en los cuales tanto el efecto aleatorio como el efecto fijo de la variable de preescolar tienen una gran relevancia. En estos, una desviación estándar del puntaje en la prueba de matemáticas equivale a 80, 77 y 87 puntos, respectivamente. Lo anterior implica que en los tres casos el efecto aleatorio de la educación preescolar en los centros educativos es de 9 puntos, 2,6 puntos y 8,9 puntos, respectivamente. Además, el efecto fijo de la variable de preescolar en estos países no solo es significativa a un alfa del $0,01 \%$, sino que presenta un coeficiente estandarizado en los tres casos con gran importancia práctica, de 0,12.

El segundo grupo incluye a México y Perú, con una varianza aleatoria alta, pero un coeficiente en la parte fija de la educación preescolar sin significancia práctica en su magnitud.

El tercer grupo incluye a Chile y Colombia, países en los cuales ni el efecto aleatorio ni el efecto medio de los grupos (parte fija) tiene significancia estadística.

Por último, se encuentra Costa Rica, que muestra la mayor variabilidad en el parámetro aleatorio pero un nulo efecto fijo. Este caso es muy particular, porque significa que si bien en media, los resultados de los estudiantes que asistieron a preescolar y los que no lo hicieron no son distintos, la variabilidad dentro de los colegios es muy alta, evidenciando que la relación entre la asistencia a la educación preescolar y el rendimiento en matemáticas sí varía entre colegios, siendo este un indicador de posibles desigualdades en el sistema educativo costarricense ${ }^{11}$.

Asimismo, el cuadro 6 muestra otros resultados interesantes para cada país, uno de los cuales es que existe una variable que es tanto significativa como de gran magnitud en los 8 países estudiados, que es al auto concepto de los estudiantes en matemáticas, mostrando nuevamente que la valoración propia de los estudiantes y su confianza hacia la materia podrían ser vitales para obtener mejores resultados, aunque aún no es clara la posible relación de causalidad: si un mayor auto concepto aumentar las habilidades matemáticas (y por ende el rendimiento) o si el tener mayores habilidades mejora el auto concepto.

Además de esta variable, el interés propio en matemáticas por parte de los estudiantes, el manejo de conceptos matemáticos básicos para la edad que tienen los estudiantes y la ansiedad al momento de resolver problemas que involucren el uso de matemáticas son variables que tienen una gran importancia en casi todos los países latinoamericanos.

11 El hecho de que efecto fijo sea nulo no significa que todos los centros educativos obtienen el mismo resultado, sino que hay unos centros con efectos positivos y otros con efectos negativos para haber asistido a pre-escolar, pero que al combinarlos, en promedio, se anulan. 


\section{CONCLUSIONES}

El Programa Internacional de Evaluación de Estudiantes (PISA) se ha enfocado en medir la calidad de la educación en diversos países alrededor del mundo, lo cual permite a las naciones y a sus habitantes conocer el nivel relativo en el que se encuentra la calidad de sus sistemas educativos. El hecho de que actualmente ocho países latinoamericanos participen en este proyecto es un avance importante, ya que les permite forjar una idea bastante clara del estado de la calidad educativa en sus países.

Los resultados de esta investigación muestran que la asistencia a la educación preescolar sí juega un rol importante en el rendimiento futuro de los estudiantes. Tradicionalmente, este efecto únicamente ha sido medido a través del efecto fijo o diferencia promedio entre los estudiantes que asistieron a este ciclo educativo y los que no. Sin embargo, este estudio muestra que la variabilidad va más allá de los efectos promedios, y que las diferencias entre centros educativos son importantes, y muestran una gran desigualdad a lo interno de los sistemas educativos que en algunos casos no compensan las desventajas de los estudiantes que no asistieron a la educación preescolar.

Además, incluso controlando por variables tradicionalmente relacionadas con el rendimiento como el estatus socio económico del hogar, o el nivel educativo de los padres, esta investigación muestra que los factores personales tienen una gran relevancia al momento de explicar las diferencias en los rendimientos educativos en matemáticas.

Particularmente, el auto concepto de los estudiantes en el área matemática, su interés hacia las matemáticas y la familiaridad con conceptos matemáticos son variables que mostraron una elevada asociación con los puntajes en la prueba PISA.

Es claro que el interés en las matemáticas y el conocimiento de conceptos matemáticos son factores que pueden ser moldeados desde los centros educativos $y$, por lo tanto, se convierten en variables relevantes para la definición de políticas educativas que mejoren la aprehensión de los conocimientos matemáticos, por parte de los estudiantes y renueven la forma en que se imparte el currículo matemático en los centros educativos, propiciando un aprendizaje que fomente el interés por la investigación, lo que además repercutirá en la confianza de los estudiantes hacia esta materia $y$, por ende, en su auto concepto sobre sus aptitudes hacia las matemáticas.

En este sentido, es importante resaltar el valioso esfuerzo realizado en Costa Rica en la reformulación de sus programas de educación matemática, que buscan contribuir significativamente a que Costa Rica supere los problemas que por muchos años han caracterizado la enseñanza de las Matemáticas.

Desde el año 2013, el país centroamericano ha introducido paulatinamente este nuevo programa, y para el ciclo lectivo 2016 ya se aplica en todo el sistema educativo. Este programa se encuentra en línea con el concepto de alfabetización matemática utilizado en PISA, donde se espera que el estudiante aprenda matemáticas para su vida cotidiana. Será hasta el año 2021 que podrá evaluarse el resultado de este nuevo programa utilizando el programa PISA, tanto porque será en ese año que la prueba vuelva a tener las matemáticas como área central de evaluación, como porque tomará también tiempo para que los jóvenes costarricenses de 15 años hayan sido afectados por dicha reforma.

Este tipo de iniciativas pueden ser aplicadas en el resto de la región latinoamericana, y aunque requieren un esfuerzo muy importante en capacitación docente, el uso de recursos tecnológicos y, posteriormente, la adecuación de los programas de educación superior para responder a estos cambios curriculares, tendrían un enorme beneficio de largo plazo para las sociedades de latinoamericanas. 


\section{AGRADECIMIENTOS}

El autor agradece la colaboración en la discusión de los resultados de la Doctora Eiliana Montero Rojas, profesora de la Universidad de Costa Rica.

\section{REFERENCIAS}

Banerjee, A. V., Cole, S., Duflo, E., \& Linden, L. (2007). Remedying Education: Evidence from Two Randomized Experiments in India. The Quarterly Journal of Economics, 122(3), 1235-1264. https://doi.org/10.1162/qjec.122.3.1235

Banerjee, A. V., Cole, S., Duflo, E., \& Linden, L. (2007). Remedying Education: Evidence from Two Randomized Experiments in India. The Quarterly Journal of Economics, 122(3), 1235-1264. https://doi.org/10.1162/qjec.122.3.1235

Barrera-Osorio, F., \& Linden, L. L. (2009). The Use And Misuse Of Computers In Education: Evidence From A Randomized Experiment In Colombia. The World Bank. https://doi.org/10.1596/1813-9450-4836

Coleman, J. (1966). Equality of Educational Opportunity. Washington D.C.: UD Deparment of Education

Cristia, J., Ibarraran, P., Cueto, S., Santiago, A., \& Severin, E. (2012). Technology and Child

Cristia, J. (2012). Technology and child development: evidence from the one laptop per child program. [IDB Working Paper Series, N ${ }^{\circ}$ 304], Washington, D.C., Department of Research and Chief Economist, Banco Interamericano de Desarrollo. Recuperado de https://publications.iadb.org/handle/11319/3919

Cristia, J., Czerwonko, A., \& Garofalo, P. (2010). Does ict Increase Years of Education? Evidence from Peru. [Working Papers, $\mathrm{N}^{\circ}$ 110], Washington, D.C., Banco Interamericano de Desarrollo. Recuperado de https://publications.iadb.org/handle/11319/3010

Fernández, A. (2013). Análisis de la Resiliencia Educativa de los estudiantes costarricenses con datos de la Prueba de Lectura de la Evaluación PISA 2009. Revista de Ciencias Económicas, 31(2), 75-99. Recuperado de http://revistas.ucr.ac.cr/index.php/economicas/article/view/12696

Fernández, A. (2014). La influencia del acceso al uso de computadoras en edad temprana sobre el rendimiento en matemáticas. Revista de Ciencias Económicas, 32(2), 113. https://doi.org/10.15517/rce.v32i2.17261

Fernández, A. (2017). Un modelo de ecuaciones estructurales bayesiano: aplicación al rendimiento matemático en PISA 2012. (Aprobado para ser publicado en la Revista Estadística Española).

Fernández, A., \& Del Valle, R. (diciembre, 2013). Desigualdad Educativa en Costa Rica: La brecha entre los estudiantes de colegios públicos y privados. Revista CEPAL, 111. Recuperado de http://repositorio.cepal.org//handle/11362/35932

Giménez, G., Arias R, R., Castro A, G., Fernández, L. J., Ospina P, N., \& Sánchez, L. (2014). ¿Por qué los estudiantes de colegios públicos y privados de Costa Rica obtienen distintos resultados académicos? (Quinto Informe del Estado de la Educación). Programa Estado de la Nación en Desarrollo Humano Sostenible, San José, Costa Rica.

Glewwe, P., Hanushek, E., Humpage, S., \& Ravina, R. (2011). School Resources and Educational Outcomes in Developing Countries: A Review of the Literature from 1990 to 2010 (No. w17554). Cambridge, MA: National Bureau of Economic Research. https://doi.org/10.3386/w17554

Glewwe, P., Kremer, M., \& Moulin, S. (2007). Many Children Left Behind? Textbooks and Test Scores in Kenya (No. w13300). Cambridge, MA: National Bureau of Economic Research.

https://doi.org/10.3386/w13300 
Hanushek, E. A. (1986). The Economics of Schooling: Production and Efficiency in Public Schools. Journal of Economic Literature, 24(3), 1141-1177.

Montero, E. (2012). Los modelos de ecuaciones estructurales como herramienta para explorar posibles relaciones causales en investigación educativa: Una ilustración con datos de PISA 2009 en Costa Rica. Aporte Especial. Cuatro Informe del Estado de la Educación. Programa Estado de la Nación en Desarrollo Humano Sostenible, San José, Costa Rica.

Montero, E., Rojas, S., \& Zamora, E. (2014). Costa Rica en las pruebas PISA 2012. Quinto Informe del Estado de la Educación. Programa del Estado de la Nación en Desarrollo Humano Sostenible, San José, Costa Rica.

Montero, E., Rojas, S., Zamora, E., \& Rodino, A. (2013). Costa Rica en las pruebas PISA 2009 de Competencia Lectora y Alfabetización Matemática. Cuarto Informe del Estado de la Educación: Programa Estado de La Nación en Desarrollo Humano Sostenible, San José, Costa Rica.

Moreira, T. E. (2009). Factores endógenos y exógenos asociados al rendimiento en matemática: un análisis multinivel. Revista Educación, 33(2), 61. https://doi.org/10.15517/revedu.v33i2.505

Muralidharan, K., \& Sundararaman, V. (2013). Contract Teachers: Experimental Evidence from India (No. w19440). Cambridge, MA: National Bureau of Economic Research. https://doi.org/10.3386/w19440

OECD. (2009). PISA Data Analysis Manual: SPSS, Second Edition. OECD Publishing. https://doi.org/10.1787/9789264056275-en

OECD. (2012). PISA 2009 Technical Report. OECD Publishing. https://doi.org/10.1787/9789264167872-en

OECD. (2013). PISA 2012 Assessment and Analytical Framework. OECD Publishing. https://doi.org/10.1787/9789264190511-en

Rojas, L. (2004). Factores Asociados a la Repitencia de los y las Estudiantes que Cursan Sétimo Año en Colegios Académicos, Diurnos y Públicos: Un Análisis de Niveles Múltiples. [Tesis doctoral]. Universidad Estatal a Distancia, San José, Costa Rica.

Tan, J.-P., Lane, J., \& Lassibille, G. (1999). Student Outcomes in Philippine Elementary Schools: An Evaluation of Four Experiments. The World Bank Economic Review, 13(3), 493-508. https://doi.org/10.1093/wber/13.3.493

Van Buuren, S., \& Groothuis-Oudshoorn, K. (2011). mice : Multivariate Imputation by Chained Equations in R. Journal of Statistical Software, 45(3). https://doi.org/10.18637/jss.v045.i03 